\title{
Significados de atividades extracurriculares para crianças bailarinas
}

\author{
Anna Paula Brandão \\ Universidade Federal da Bahia - Salvador - BA - Brasil \\ Lia da Rocha Lordelo \\ Universidade Federal do Recôncavo da Bahia - Cruz das Almas - BA - Brasil
}

\begin{abstract}
Resumo
Este estudo investigou o cotidiano de crianças da classe média em Salvador, Bahia. A pesquisa foi realizada em uma escola de balé com meninas entre seis e sete anos de idade. Para a coleta de dados, foi feita observação não estruturada de caráter etnográfico e exploratório na escola de balé e entrevistas-conversa com cinco crianças. Os resultados apontam para os sentidos ambivalentes que circunscrevem o balé entre as dimensões da disciplina e do lúdico, além do status de hiperocupação, que constitui um ponto que une as crianças do presente estudo e nos faz refletir sobre as representações da infância atualmente. Na medida em que surgem cada vez mais instituições especializadas em ofertar atividades para crianças, os resultados indicam que os ambientes em que se desenvolvem atividades extracurriculares permanecem ainda pouquíssimo explorados no Brasil; e discutem, também, a necessidade de investigar mais essa infância, invisibilizada por ser considerada normativa.
\end{abstract}

Palavras-chave: Crianças; dança; atividades extra-curriculares.

\section{The meanings of extracurricular activities for ballarinian children}

\begin{abstract}
This study investigated the daily life of middle-class children in Salvador, Bahia. The research was developed at a ballet school with girls between six and seven years. The collection of data was done by an unstructured observation of ethnographic and exploratory character in ballet school and interviews with five children. The results point to the ambivalent meanings that circumscribe the ballet between the dimensions of the discipline and the playfulness, as well as the status of hyperactivity, which constitutes a point that unites the children of the present study and makes us reflect on the representations of childhood today. As more and more institutions specialized in offering activities for children appear, the results indicate that the environments in which extracurricular activities are developed are still scarcely explored in Brazil; and also discuss the need to investigate this childhood, which is invisible because it is considered normative.
\end{abstract}

Keywords: Children; dance; extracurricular activities.

\section{Significados de actividades extracurriculares para niños bailarinos}

\section{Resumen}

En este estudio se investigó el cotidiano de niños de la clase media en Salvador, Bahía. La investigación se realizó en una escuela de balé con niñas entre seis y siete años de edad. Para la recolecta de datos, se hiso observación no estructurada de carácter etnográfico y exploratorio en la escuela de balé y entrevistas-conversa con cinco niños. Los resultados apuntan para los sentidos ambivalentes que circunscriben el balé entre las dimensiones de la asignatura y del lúdico, además del status de híperocupación, que constituye un punto que une los niños del presente estudio y nos hace reflexionar sobre las representaciones de la infancia actualmente. En la medida en que surgen cada vez más, instituciones especializadas en ofrecer actividades para niños, los resultados indican que los ambientes en que se desarrollan actividades extracurriculares permanecen aún poquísimo explorados en Brasil; y discuten, también, la necesidad de investigar más esa infancia, invisibilizada por ser considerada normativa.

Palabras clave: Niños; danza; actividades extracurriculares. 


\section{Introdução}

Este artigo, fruto de um recorte do trabalho de iniciação científica, tem por objeto as atividades extracurriculares exercidas por crianças no contra turno da escola, no contexto da classe média/alta na cidade de Salvador, Bahia. O interesse por este tema decorreu de resultados e reflexões produzidos a partir de pesquisas recentes (Chaves \& Lordelo, 2012; Lordelo, 2014, 2015), em que eram investigados os significados de trabalho e de infância para crianças de diferentes contextos culturais, entre crianças trabalhadoras e não trabalhadoras. De tal pesquisa sobre trabalho, três questões relevantes foram levantadas: primeiro, a variedade de significados referentes ao trabalho que as crianças produziram, independente de serem ou não trabalhadoras; depois, a percepção do dever de casa e de rotinas escolares como atividades próximas de um tipo de trabalho - na medida em que estas ocupam as crianças e são vistas como obrigações, o que se relaciona com reflexões da sociologia da infância, que entendem a criança escolar como a nova criança trabalhadora (Qvortrup, 1987, 2001); e finalmente, a preocupação predominante com situações de extrema pobreza e exploração da mão-de-obra infantil, revelada pela literatura brasileira principalmente, que nos alerta para a necessidade de estudarmos situações menos "visíveis" de trabalho na infância (Aldridge, 2008; Crafter, O’Dell, Abreu, \& Cline, 2009; Melro, 2010). Assim, passamos a nos perguntar: para crianças de classe média, as quais se encontram na escola, cuidadas e protegidas pela família, qual o significado de seu engajamento em atividades extracurriculares? A partir dessa pergunta, passamos a entender e a justificar a necessidade de direcionarmos nosso olhar para contextos de aprendizagem e formação extraescolares, compreendendo os significados, para crianças, das atividades regulares que são de alguma forma independentes da rotina escolar.

Entre as muitas e diversas atividades extraescolares praticadas por crianças de classe média/alta, as pesquisadoras investigaram a rotina das crianças na escola de balé; as escolas de dança são contextos bastante comuns para o exercício de atividades extracurriculares, em particular no caso de crianças de classe média/alta, nos dias atuais.

A partir dessas reflexões, o objetivo central deste trabalho é conhecer o cotidiano de crianças de classe média/alta que frequentam intensamente atividades extracurriculares no turno oposto ao da escola. As perguntas que norteiam o estudo de forma mais ampla são: como é a infância de uma criança - no caso, uma menina - que frequenta ativamente o balé, em paralelo à escola? Como essas diferentes atividades organizam e dão sentido a seu dia-a-dia? Que relação as crianças estabelecem com esta atividade extracurricular em especial?

\section{Fundamentação Teórica}

Este estudo é teoricamente amparado pelo campo dos estudos sociais da infância, a partir de autores como
Sarmento (2007), James, Jenks e Prout (1998) e Sirota (2001), e assenta-se sobre um pressuposto teórico primeiro: a vida concreta das crianças só pode ser analisada no contexto social cujas imagens e representações determinam aquilo que se constitui enquanto infância. Castro (1998) nos lembra de que se entendermos, sem muito questionar, que ser criança é brincar, ir à escola, morar com a sua família, estar livre de responsabilidades etc., é justamente porque a infância é naturalizada através de tais práticas, as quais a circunscrevem na modernidade. Decerto essa imagem hegemônica de infância corresponde majoritariamente a crianças socialmente protegidas, já que essa infância projetada pela modernidade nunca foi aplicável a todas as classes sociais. Isso não significa, no entanto, que todos não irão sofrer o impacto dessa representação social mais ampla.

Os estudos sociais da infância, especialmente a Sociologia da Infância, têm abordado ou apresentado esta infância descrita por Castro (1998) como uma infância típica, de classe média, e que, aparentemente, não sofre vulnerabilidade econômica e/ou social. No entanto, para grande parte desse campo de investigações, principalmente no contexto brasileiro, sabe-se pouco sobre os modos de vida, as vivências e especialmente as demandas que emergem entre as crianças consideradas como protegidas e inseridas socialmente.

Para Sarmento (2007), a infância sofre precisamente um processo de ocultação, na medida em que temos lidado prioritariamente com concepções já estabelecidas sobre ela. Neste sentido, as crianças de classe média ou alta acabam por ser duplamente invisibilizadas. Se por um lado, são tratadas como crianças que seguem um curso esperado e "natural" do desenvolvimento, elas podem ser, por outro, negligenciadas em suas peculiaridades (Santana \& Lordelo, 2014; Brandão \& cols., 2013).

Também por esse motivo, surgiu a necessidade de pesquisa de escutar as crianças prioritariamente; considerar a infância como um grupo social com voz própria requer, de acordo com Montandon (2001), que vejamos as crianças não como seres em amadurecimento ou desenvolvimento progressivo, mas com uma espécie de olhar fenomenológico que se interessa pela experiência das crianças em si e pelo seu papel de atores.

O levantamento de literatura sobre atividades extracurriculares no Brasil mostrou uma escassez de estudos sobre o tema. Os estudos encontrados no contexto brasileiro apontaram a importância da atividade extracurricular para ocupar o "tempo livre" das crianças, isso é, o turno que elas não estariam na escola. Entre a população de maior vulnerabilidade socioeconômica, foi encontrada a predominância do uso do tempo livre em atividades não estruturadas, sendo que esse tipo de atividade não seria promotora de proteção e segurança aos adolescentes estudados, e sim vulnerabilidades como comportamentos de risco, uso de drogas e violência (Sarriera, Tatim, Coelho, \& Bucker, 2007).

Os atuais estudos acerca da educação integral no Brasil (Mancini \& Castanho, 2016) apontam para uma relação entre as escolas de tempo integral e a tentativa de oferecer proteção a crianças e jovens em riscos relaciona- 
dos à vulnerabilidade socioeconômica. Colocam também a necessidade de reconhecer o direito à educação integral como promotora de outros benefícios aos estudantes, além da proteção ao risco, aspecto amplamente investigado. Matias (2009) destaca a importância de investigar os ganhos em aspectos do desenvolvimento para esse público.

Mancini e Castanho (2016) apresentam estudos que reconhecem o aumento do tempo escolar no Brasil; as autoras, entretanto, percebem a escassez de estudos que avaliam os impactos da jornada escolar ampliada no desenvolvimento e aprendizagem das crianças e jovens.

Na literatura internacional, há estudos relacionando atividades extracurriculares com aumento de saúde e bem-estar (Bungay \& Vella-Burrows, 2013), melhoria de desempenho acadêmico, assim como de habilidades não-cognitivas (Covay \& Carbonaro, 2010) e com a preocupação em não deixar crianças sozinhas em casa (Larner, Zippiroli, \& Behrman, 1999). Covay \& Carbonaro (2010) correlacionam a participação em atividades extracurriculares com questões socioeconômicas, sendo que crianças de classes sociais média/alta participam de um número maior de atividades quando comparadas a crianças de classes pobres.

Durlak, Weissberg, e Pachan (2010), ao investigarem programas de atividades extracurriculares que buscam aprimorar habilidades pessoais e sociais em crianças e adolescentes, perceberam um aumento significativo na adesão à escola e nos comportamentos sociais positivos, notas escolares e realização acadêmica, compreendendo que alguns programas podem ser mais bem sucedidos do que outros no incremento de benefícios como os mencionados acima.

Dryfoos (1999) argumenta para a necessidade de atenção à criança no período fora da escola, não apenas por considerar arriscada a falta de supervisão de adultos em casa, mas também por reconhecer que o período escolar não é suficiente para o aprendizado da criança, sendo necessários investimentos educativos no turno oposto ao da escola. Larner e cols. (1999) ressaltam que há uma expectativa por parte dos adultos de que as crianças descubram talentos individuais e escolham as atividades que vão lhes preparar para a vida adulta.

Kremer-Sadlik, Izquierdo, e Fatigante (2010) investigam significados de atividades extracurriculares para pais de crianças italianas e americanas, sendo que, para os pais italianos, a atividade extracurricular é vista como uma atividade que faz parte do "mundo das crianças", enquanto que para os pais americanos ela representa uma preparação para a vida de adulto, enfatizando aspectos relacionados a sucesso e competição.

Mahoney, Harris, e Eccles (2006) e Mahoney \& Vest (2012) investigaram a teoria das agendas superlotadas para crianças e adolescentes e contrapondo aos benefícios das atividades extracurriculares. Os estudos consideram que há grandes benefícios nessas atividades organizadas. Mahoney e cols. (2006) notam que a vasta maioria dos adolescentes não participa de nenhuma atividade e que esse fato ainda se mostra bastante prejudicial e orienta ações para investir em atividades extracurriculares.
Mahoney (2014) relaciona as atividades extracurriculares à influência dos grupos de pares para investigar a evasão precoce da escola. Esse estudo observa que, quando o adolescente e o seu grupo de pares participam de atividades extracurriculares, há um menor risco de abandono escolar precoce.

Com exceção do estudo de Kremer-Sadlik e cols. (2010), notamos a falta de estudos que investigam e analisam a infância de classe média/alta, principalmente no Brasil. Relacionamos esse achado com a invisibilização de possíveis riscos atrelados a uma infância que não sofre de vulnerabilidade social e econômica, reiterando a tese de que é necessário produzir estudos sobre a infância em diferentes contextos de desenvolvimento.

\section{Método}

O estudo foi realizado a partir de duas principais técnicas: observação não estruturada de caráter etnográfico e exploratório, registrada por meio de diários de campo (Macedo, 2006); e entrevistas-conversa realizadas com crianças e suas mães e/ou responsáveis (Saramago, 2001). As entrevistas realizadas com as mães e/ou responsáveis constituíram um corpus complementar de informações para a discussão, produzindo uma triangulação com os dados gerados pelas entrevistas com as crianças e as observações exploratórias.

A observação de caráter etnográfico foi realizada no ambiente da escola de balé, em uma turma com meninas entre seis e sete anos. Conquanto a pesquisa não se configure propriamente como uma etnografia, o caráter livre das observações, aliado ao período e a frequência com que foram feitas, dão a elas uma dimensão etnográfica. As aulas aconteciam duas vezes na semana e tinham aproximadamente uma hora de duração cada. Após a fase de observação das aulas, entramos em contato com sete meninas dessa turma e com seus respectivos responsáveis para a realização das entrevistas-conversa com as crianças. A participação na pesquisa ocorreu após a explicação de seus objetivos e da assinatura do Termo de Consentimento Livre e Esclarecido, para os responsáveis, e do Termo de Assentimento para as crianças. O período de observação na escola de balé durou cerca de dois meses.

A entrevista-conversa teve como objetivo compreender como as crianças relacionam-se com a escola de balé e com diversas atividades desempenhadas por elas durante a semana, entendendo que muitas crianças de classe média e alta têm se envolvido com frequência e intensidade em atividades extracurriculares.

A entrevista-conversa (Saramago, 2001) é uma técnica de pesquisa que conduz a investigação de modo que a criança ocupe espaço central na entrevista, tendo assim a liberdade de conduzir a conversa a partir de sua fala espontânea. A partir dos procedimentos sistematizados na técnica da análise de conteúdo (Bardin, 2006), grandes blocos temáticos foram investigados na entrevista Infância, 
Escola, Escola de balé e Tempo livre - a partir dos quais as conversas aconteciam e as unidades de registro foram construídas.

\section{Resultados}

Os resultados aqui descritos referem-se, em primeiro lugar, à observação feita no ambiente da escola e nas aulas de balé e, em seguida, às entrevistas-conversa feitas com as meninas participantes do estudo.

\section{Observação: A Escola de Balé}

A escola de balé localiza-se dentro de um clube de lazer e atividades físicas ou esportivas. Ela é decorada com enfeites de bailarinas clássicas e com troféus de competições em dança. Além das três salas de aula, há um parquinho, um vestiário e um espaço onde os responsáveis costumam arrumar as crianças e esperá-las durante as aulas.

A farda da escola é obrigatória e inclui: collant, meia calça, sapatilha, rede para o coque e cinto. Esta é padronizada e deve ser adquirida através da escola. O uso da farda completa é constantemente cobrado pela professora. A falta de um ou mais itens incorre em reclamações ou proibição da participação da criança em parte da aula. Notamos a existência de um sistema de estabelecimento de notas para a farda das crianças: a professora avalia cada criança conferindo uma nota à sua farda (de acordo com o cumprimento dos itens obrigatórios) e fazendo possíveis elogios ou reclamações. Diante dos comentários, as crianças, em geral, vibram de alegria ao receberem um 10 ou lamentam por terem recebido nota inferior. Em alguns casos, as crianças justificam a falta de algum item da farda explicando que os seus pais ainda não o compraram.

A observação de caráter etnográfico teve início em outubro de 2013 e foi finalizada em fevereiro de 2014 (com pausa para as férias entre dezembro e janeiro), sendo que foi possível acompanhar algumas mudanças ocasionadas pela evolução de grau no sistema do balé. Em 2013, as alunas tinham duas aulas por semana com uma hora de duração cada.

A observação começou no mesmo período em que a escola iniciou as preparações para a formatura e para o festival do final de ano. A formatura é um evento que acontece anualmente na escola e envolve as turmas que estão passando por uma transição considerada muito importante no método de balé. A turma acompanhada realizou a transição para os chamados "grades" (palavra inglesa que designa o grau de dificuldade da turma). Devido à mudança de grau, as meninas terão mais um dia de prática de dança na escola: sendo assim, a partir do ano seguinte, elas passaram a ter aulas de jazz em um terceiro dia na semana.

O festival de final de ano é um evento bastante comum entre as escolas de dança. Esse festival é construído a partir de um tema escolhido pela diretoria da escola.
Nesse ano, o festival foi baseado em uma história fictícia de uma menina que não tinha tempo livre. Ao narrar o tema do festival para as crianças, a professora mencionou a falta de tempo das crianças atualmente, referindo-se à escola e às diversas atividades que as crianças geralmente fazem: inglês, balé, natação etc., cita a professora.

Numa das aulas observadas, a professora comenta conosco sobre a ausência de uma das meninas nas aulas dessa semana, justificando que a criança "tirou uma semana de férias" porque ela estava se sentindo cansada e sobrecarregada. Ainda sobre o festival, ela pergunta às crianças, durante a aula em que apresenta o tema, se não seria bom ir para um mundo onde tudo é "diversão e fantasia".

Há uma grande preparação em torno da formatura e do festival, tratando-se de momentos considerados muito importantes para a escola de balé. A coordenadora nos informou que esse é um momento crítico em que as alunas eram mais cobradas do que no restante do ano. No entanto, foi observado no início das aulas regulares que a rigidez e disciplina continuavam sendo características marcantes na rotina das aulas, sendo necessário considerar que a progressão no método de balé também é motivo para aumento de demandas e exigências.

É possível traçar um roteiro básico para a estrutura das aulas de balé a partir da observação. Em um primeiro momento, a professora faz a chamada anotando a presença e as faltas, sendo que as faltas são sempre questionadas. Eventualmente ela comunica algumas informações e entrega avisos para serem repassados aos responsáveis pelas crianças. Em geral, a professora sempre faz comentários sobre as fardas das alunas, chama atenção para a falta de algum item, para o cabelo bagunçado ou se a farda não estiver arrumada adequadamente, podendo utilizar o sistema de notas que mencionamos acima.

A aula vai começar! As alunas organizam-se em filas e a professora indica a ordem em que elas devem se organizar, qual ficará na frente ou atrás. Algumas crianças questionam o fato de não serem colocadas na frente, sendo que a professora busca cessar esse questionamento pedindo para a criança ficar no seu lugar e se comportar. As sequências de passos são ensinadas pela professora e as crianças devem copiá-la. Se a sequência já foi ensinada antes, as crianças devem lembrar sem ajuda da professora. A professora costuma punir com reclamações quando as alunas não se lembram da sequência que já foi ensinada. Em alguns casos, apenas uma ou duas alunas lembram-se da sequência. Se a professora percebe que toda a turma está copiando uma ou duas colegas, ela pune a turma e exalta as qualidades daquelas que se lembram das sequências.

Os passos e movimentos são ensinados com ênfase nos detalhes, sendo que, diante de alguns erros, a professora para a música para corrigir as alunas, expondo o erro para toda a turma. Muitas delas ficam envergonhadas com as reclamações, mas há também algumas alunas que dão risada e demonstram não se preocupar com a rigidez técnica. No final de uma das aulas, a professora comenta conosco sobre o comportamento efusivo e alegre de uma 
Tabela 1. Descrição das atividades desempenhadas pelas participantes.

\begin{tabular}{lll}
\hline Participante & Idade & Atividades \\
\hline Ana & 7 anos & $\begin{array}{l}\text { Pratica balé, faz teatro e tem aulas de piano. Pretende começar as aulas de natação e ginástica } \\
\text { rítmica e continuar os estudos de piano em casa com sua avó. }\end{array}$ \\
\hline Maria & 7 anos & Pratica balé, ginástica rítmica e capoeira. \\
\hline Lara & 7 anos & Pratica balé, ginástica rítmica e capoeira \\
\hline Joana & 6 anos & Pratica balé e pretende começar aulas de equitação. \\
\hline Sara & $\begin{array}{l}\text { Pratica balé e natação, sendo que, durante o período da observação na escola de balé, ela troca a } \\
\text { natação pela capoeira. Já fez aulas de circo e tem o desejo de fazer aula de teatro. }\end{array}$ \\
\hline
\end{tabular}

das alunas. Ela fala com pesar sobre a necessidade de que o comportamento "alegre demais" seja tolhido e justifica isso se referindo à "sociedade que não é assim" e por isso "eu tenho que cortá-la", justifica.

\section{Entrevistas}

A análise dos blocos temáticos construídos a partir da entrevista-conversa representa a tentativa de compreender como as crianças se situam no cenário descrito e analisado acima.

A partir do contato e entrevistas com as sete crianças participantes, foram analisadas cinco entrevistas, as quais produziram mais informações no contato com a entrevistadora. As participantes (os nomes são pseudônimos) são:

\section{Blocos temáticos:}

\section{INFÂNCIA}

As crianças compreendem a Infância como o período de brincar: em todas as respostas ao bloco, há a alusão ao brincar e às brincadeiras, sendo que cada criança se relaciona com essa compreensão de maneiras diferentes. Ana considera que ser criança é brincar e se divertir, mas ela diz não ser muito assim porque sua mãe não a deixa brincar sozinha na rua, demonstrando uma compreensão de infância como um momento de brincar livremente, sem supervisão de adultos. Maria coloca que "ser criança é brincar, me divertir, mas acima de tudo meus deveres". Ela confere à brincadeira e à diversão um lugar importante na sua infância, mas destaca que "a obrigação vem primeiro da diversão". Enquanto a maioria das meninas coloca as atividades da escola como uma parte negativa da infância, Maria afirma que ama fazer atividades e estudar. Mesmo assim, Maria destaca em muitos momentos da entrevista a sua relação com o brincar. Muitas falas surgiram sobre a relação entre a infância e a obrigação com o dever de casa.
Quando perguntada sobre a pior parte em ser criança, Lara responde: "Ah, eu tou com vergonha de falar" e se refere ao dever de casa, demonstrando uma compreensão de que há algo de errado ou indesejável em não gostar das atividades da escola. Já Joana afirma, entre as diversas brincadeiras da sua infância, que "faz várias coisas importantes". Ao questioná-la sobre isso, ela diz que "as coisas importantes das crianças é fazer dever de casa", sendo que durante a entrevista ela coloca o dever de casa como uma parte negativa da infância.

Ana ainda coloca que sua vida é um pouco de criança e de adulto: "mais ou menos as duas coisas... porque esse ano eu tenho que ter muita responsabilidade de adulto porque eu vou pra escola em tempo integral aí vai ser mais difícil e de outro lado eu sou muito criança porque eu gosto de brincar bastante". Ela ratifica o brincar como característica importante que a define como criança.

De um modo geral, as meninas, mesmo não gostando das atividades da escola, consideram essas importantes. A brincadeira e o dever de casa surgiram como as principais características da infância para essas meninas.

\section{ESCOLA}

Em geral, elas entendem que a Escola tem por função ensinar e passar deveres - uma compreensão bastante compartilhada socialmente. Ao serem perguntadas sobre o lado bom da escola, mais uma vez as brincadeiras aparecem com frequência, sendo que o recreio e a educação física são vistos como momentos de brincar e esses momentos são avaliados positivamente por elas. Outro ponto que surge sobre o lado bom da escola é a questão da sociabilidade. Muitas crianças apontaram a escola como um momento de encontrar colegas e professores. Quando perguntamos à Ana qual a melhor parte da escola, ela responde: "conhecer novos amigos e brincar!". Os deveres de casa são considerados a parte ruim da escola. Além disso, surgem também como pontos negativos os professores de que elas não gostam e as brigas com os colegas. Sobre a escola, Maria 
responde: "é me divertir, fazer minhas obrigações e brincar com os meus amigos", sintetizando as respostas das meninas ao se referirem à brincadeira, obrigações e à questão da sociabilidade, pontos bastante explorados nas respostas de todas as entrevistadas.

\section{O BALÉ}

A relação das meninas com a Escola de balé é caracterizada, em geral, pelo aspecto da sociabilidade, pela importância do aprimoramento e progressão no balé e pela relação com o mundo do espetáculo. Ao perguntar pra Joana porque ela decidiu entrar no balé, ela explica: "porque eu soube que Lara ia fazer balé, aí eu queria me juntar com ela e como Renata já estava no balé, Lara também quis ir pro balé e também eu me juntei com elas duas pra poder ir pro balé. Porque eu ficava mais tempo com elas duas." Na fala de Joana, percebemos uma forte influência do grupo de pares na entrada das meninas no balé e isto está presente nas entrevistas com as outras meninas também, seja influenciando para que elas comecem o balé ou para que elas permaneçam na atividade. Vejamos o exemplo de Sara, que já teve intenção de sair do balé diversas vezes. Quando perguntamos por que ela continua, Sara responde: "Porque depois eu desisto aí as meninas que já estão na minha fase vão lá pro preto (corresponde ao grau no método de balé) e eu fico aqui.", demonstrando uma intenção em acompanhar suas colegas de turma e não ficar atrasada em relação a elas. Isso remete à evolução no método de balé como um fator importante para as meninas. Por vezes, elas referem-se ao desejo de avançar para os graus mais elevados e se aproximar mais da imagem romântica da bailarina, atrelada à perfeição e beleza. Joana coloca, por exemplo, que "dá uma vontade assim muito grande da gente avançar assim... pra um nível muito avançado que é a ponta." (ponta se refere à sapatilha de ponta utilizada pelas bailarinas mais avançadas e experientes no balé). Maria, por sua vez, diz que "via as bailarinas na TV e queria ser como elas".

Podemos pensar, então, na influência da hierarquia dos níveis do balé e no status que isso pode representar para essas meninas como um fator que, de certa maneira, regula a permanência delas no balé. Outro ponto que aparece nas entrevistas-conversa é o espetáculo. $\mathrm{O}$ balé é uma atividade extracurricular que culmina anualmente em uma apresentação em palco; as meninas fazem uma avaliação positiva de suas experiências em apresentações, e se mostram bastante animadas com o figurino do espetáculo e todo o "glamour" envolvido no evento. Sobre a relação com o espetáculo, Maria diz que "adora ir ao teatro, adora fazer as apresentações. Na minha formatura (no balé) eu fiquei tão emocionada" e Ana relata bastante desenvoltura na sua relação com o palco, sendo que das cinco atividades em que ela está envolvida, três têm uma relação direta com apresentações em espetáculo.

\section{TEMPO LIVRE}

A maioria das meninas afirma que o Tempo livre é destinado à brincadeira. Ana afirma que este é "o tempo que a gente não tem nada pra fazer, aí arranja alguma coisa pra fazer: brincar!". Para Joana, o tempo livre é "quando eu faço o dever de casa", ela explica: "Agora que eu já tou também na fase da prova, minha mãe não vai deixar eu sair tanto (sair para área em comum do condomínio onde ela mora para brincar com as outras crianças) porque agora eu já aumentei, agora eu já tou em ciências, matemática, inglês, geografia...". Ana afirma também que não tem tempo suficiente para brincar devido à quantidade de atividades que ela tem durante a semana e que isso "atrapalhou meu tempo livre". Para Maria, que tem três atividades extracurriculares, o tempo livre é "o tempo d'eu brincar e descansar" e afirma que no tempo livre ela gosta de assistir televisão e brincar com suas amigas ou com seus brinquedos. Lara, que também tem três atividades extracurriculares, gostaria de "poder brincar mais", ela acha que brinca "muito pouco" por causa do dever de casa. Lara e Maria desempenham a mesma quantidade de atividades extracurriculares e fazem avaliações diferentes com relação ao tempo livre e a disponibilidade para brincar, demonstrando que a relação das crianças com suas rotinas é bastante diferente e pode ser independente da quantidade de atividades desempenhadas por elas.

Apesar das afirmações sobre a falta de tempo suficiente para brincar ou do desempenho de muitas atividades durante a semana, todas as crianças fazem referências ao brincar como uma atividade que faz parte de suas rotinas.

\section{Discussão}

"Esse é um A de água, né, Pró?", pergunta uma das alunas sobre um movimento coreográfico que elas deveriam repetir, "Vem, vem! Sem brincar!", responde a professora. A disciplina no balé clássico está presente desde o questionamento em relação às faltas nas aulas, passando pelo rigor da farda até o aprendizado em sala de aula. A professora tem um prazo para estar com a coreografia pronta e bem ensaiada, sendo que o brincar parece não caber no cronograma.

Assim, percebemos que, em uma atividade que remete ao criativo e lúdico - nesse caso, o balé clássico, que evoca muitas estórias e enredos em sua tradicional relação com o mundo do espetáculo -, o espaço de criação e significação em sala de aula por parte das crianças é reduzido. A fala das crianças é constantemente tolhida e o momento da aula é voltado, sobretudo, para a repetição do movimento e aprimoramento técnico. Essas características não deixam de se relacionar com as tradicionais significações do balé clássico; para Théofile Gautier, poeta, escritor e crítico literário no século XIX, a dança tinha o objetivo de mostrar belas formas em uma arte puramente visual e sem participação humana (Garaudy, 1980). 
Os erros por parte das alunas, na coreografia, são apontados com reclamações e suas performances são comparadas, buscando o estabelecimento de um padrão de excelência. Como já foi citado, há o estabelecimento de fileiras em uma ordem escolhida pela professora, sendo que as alunas questionam à professora o fato de não ocuparem a primeira fileira.

"Entrevistadora: Como é a sua relação com a professora?

Ana: (Risos) Deixa eu ver... não o normal, porque ela briga muito comigo.

Entrevistadora: É? Como você acha que seria uma relação normal?

Ana: Normal... que ela brigasse pouco. Isso é normal. Como com as outras meninas. Só que tem umas que são excelentes.

Entrevistadora: Por que você acha que algumas são excelentes?

Ana: Ah, são moles... fazem os passos direito. Como Maria e Joana."

Nesse trecho da entrevista-conversa, Ana mostra compreender que existem tratamentos diferentes para as alunas de acordo com o desempenho de cada uma.

Foi possível, ainda, perceber que a preocupação com o comportamento e a disciplina em sala de aula aproxima-se da imagem de meninas bem comportadas, revelando uma associação entre gênero e comportamento. Em sala de aula, a professora faz alguns comandos correlacionando o movimento a uma imagem feminina um tanto estereotipada: por exemplo, ela pede que as meninas façam "uma corrida de salto alto", pois essa é a corrida elegante da bailarina, segundo a professora.

Para as meninas, esses aspectos atrelados a uma imagem típica da feminilidade parecem ter uma face encantadora. Sara, por exemplo, afirma que no balé ela deve se comportar como uma "madame", considerando isso positivo, apesar de ser um pouco complicado pra ela por precisar se esforçar muito para estar com "barriga pra dentro, peito pra fora, bumbum pra dentro!", o que Sara considera difícil. Ana condensa essa imagem da bailarina em sua poesia, ela se refere à bailarina como alguém "sempre elegante" e "sempre feliz".

A escolha do tema do festival nos mostra que a escola compreende duas imagens da infância: uma infância das crianças ocupadas e "sem tempo para nada", como relatou a professora, e outra infância em que tudo é diversão e fantasia. A imagem da infância "sem tempo pra nada" conecta-se com a fala de Ana, quando ela relata que terá mais responsabilidade de adulto por causa da sua escola em tempo integral e encontra eco nos estudos de Qvortrup
(1987, 2001) sobre a criança escolar contemporânea como a nova criança trabalhadora do século XXI.

É elucidativo pensar as imagens da infância e em como estas imagens sofrem modificações ao longo da história; sabemos, nesse sentido, que a noção de infância é uma invenção que data do início da modernidade (Ariès, 1981), e a partir dessa instituição, ela se torna, gradualmente, uma etapa de vida «com regras pedagógicas adequadas a seu desenvolvimento, objetivando preservá-lo do mundo conflitivo dos adultos» (Corazza, 2004, p.25). Se a infância foi construída, preservando-a e distinguindo-a do mundo dos adultos, hoje percebemos uma aproximação entre o universo infantil e o universo do adulto trabalhador com uma rotina de responsabilidades através da imagem da criança escolar contemporânea.

O modo-de-produção capitalista inaugura uma série de modificações nas relações do ser humano com o trabalho, mudanças que continuam em evolução ao longo da história e que, de certa maneira, estão conectadas com as modificações da escola, desde a sua criação até os modelos de escola que vemos hoje, com o fortalecimento, por exemplo, das escolas de tempo integral. No contexto das políticas públicas brasileiras, esse modelo de escola tem sido priorizado como uma estratégia voltada para a infância em vulnerabilidade social, sendo que a participação em atividades extracurriculares teria a função de proteger esse público (Matias, 2009). E para a infância que não está em vulnerabilidade social? Qual seria a justificativa para o investimento em tais atividades extracurriculares e em escolas de tempo integral?

Em uma pesquisa desenvolvida em Roma (Itália) e em Los Angeles (EUA), buscou-se o significado de atividades extracurriculares para os pais das crianças. Apesar das diferenças nos dois contextos, os pais italianos e americanos acreditam que esses ambientes são importantes no desenvolvimento de competências e habilidades pessoais atrelados principalmente à organização de uma rotina com responsabilidades, bem como aos ganhos específicos que cada atividade pode trazer. Dessa forma, os pais investem em atividades extracurriculares com o objetivo de garantir que seus filhos não estejam perdendo oportunidades que possam contribuir para os seus avanços (Kremer-Sadlick \& cols., 2010).

Ao apresentar o termo de consentimento, afirmamos que o "Nosso objetivo é conhecer a rotina de vocês...", nesse momento Ana interrompe a leitura e começa a citar: "judô, GR, balé... deixa eu ver... karatê, natação...”. A proliferação desses espaços institucionalizados e voltados para as crianças indica uma certa normatização das agendas infantis em que é importante estar ocupado com atividades de diferentes naturezas. De modo diferente das crianças cujo trabalho representa renda para a manutenção da casa e da família - a infância pobre protegida pelo Estatuto da Criança e do Adolescente (Lei $n^{\circ} 8.069$, 1990) contra formas de trabalho compulsórias e que colocam a criança em risco - as crianças de classe média/alta parecem estar protegidas pela crença de que seus estilos de vida são fundamentais na garantia de 
um futuro próspero. As suas rotinas super ocupadas representam, então, capital não econômico, mas social e cultural (Levey, 2009; Miller, 2005; Qvortrup, 2005; Zelizer, 2005) e que prepara essas crianças para lidar com a vida de adulto.

E para as crianças? Como elas significam suas rotinas e, em especial, o balé clássico? Há um consenso entre as crianças nesse estudo de que a infância se constitui como o período de brincar e fazer o dever de casa, a primeira atividade sendo positiva, e a segunda tendo uma dimensão negativa para boa parte das meninas entrevistadas. Perguntamo-nos, então, se o balé estaria classificado em algum lugar entre essas duas características da infância. Ao que parece, a relação com essa atividade extracurricular flutua entre essas duas categorias. Aproxima-se da noção de dever quando diminui o tempo livre semanal que poderia ser dedicado à brincadeira e também por ter uma estrutura que exige alto desempenho e culmina em resultados e possível progressão. Por outro lado, aproxima-se da noção de brincadeira, quando proporciona o encontro de pares e possibilita uma relação com o status da bailarina em sua face romântica - algo que se mostra presente na maioria do discurso das meninas entrevistadas.

O festival e a formatura, mesmo sendo momentos de cobranças e muitos ensaios - face mais próxima do dever - também remetem à fantasia e à representação de personagens, sendo que as meninas avaliam positivamente a participação nesses eventos.

A relação entre tempo livre e desempenho de atividades extracurriculares parece ser muito mais complexa que a avaliação da quantidade de atividades desempenhadas pelas crianças. Todas as entrevistadas estão envolvidas em, pelo menos, mais de uma atividade extracurricular, sendo que a percepção da falta de tempo livre para brincar nem sempre está relacionada com maior quantidade de atividades. Isto pode indicar que as crianças se relacionam de maneira diversa com a atividade desempenhada.

\section{Considerações Finais}

Compreendendo que o desempenho de atividades extracurriculares faz parte da rotina de grande parte das crianças de classe média/alta, consideramos a necessidade de ir até esses contextos na tentativa de captar essa infância que, por ser considerada normativa, é também invisibilizada, o que se expressa através da baixa quantidade de estudos com esse público-alvo. Sendo assim, o presente trabalho teve o propósito de investigar os significados dessas atividades a partir das crianças bailarinas.

O contexto escolhido para a investigação permitiu a análise de questões específicas, como os sentidos ambivalentes que circunscrevem o balé entre as dimensões da disciplina e do lúdico, além das questões relativas ao universo tipicamente feminino no balé clássico. Em um sentido mais amplo, o status de ocupação é um ponto que une as crianças do presente estudo e nos faz refletir sobre as representações da infância nos dias atuais, em que vemos surgir cada vez mais instituições especializadas em ofertar atividades para crianças - atividades extracurriculares, espaços com jogos e videogames, grupos que organizam brincadeiras, gincanas e festas etc. - além do crescimento de escolas em tempo integral. Os ambientes em que se desenvolvem atividades extracurriculares - seus atores sociais, os motivos que levam as crianças a frequentá-los; suas dinâmicas de funcionamento etc. - permanecem ainda pouquíssimo explorados no Brasil; investigá-los mais detidamente é um modo de compreender e enxergar novos matizes da infância contemporânea.

\section{Referências}

Aldridge, J. (2008). All work and no play? Understanding the needs of children with caring responsibilities. Children \& Society, 22, 253-264.

Ariès, P. (1981). História Social da Criança e da Família. Rio de Janeiro: LTC.

Bardin, L. (2006). Análise de conteúdo (L. de A. Rego \& A. Pinheiro, Trads.). Lisboa: Edições 70. (Trabalho original publicada em 1977).

Brandão, A.P., Bezerra, C.S.M., Santana, J.P., Lordelo, L.R., Avanzo, J.R., Liborio, M.M., Gonzaga, P.R.B., Lepikson, B.B., Bichara, I.D., \& Cunha, J. (2013). Infâncias Normativas: ressignificando a vulnerabilidade, risco e bem-estar de crianças. Trabalho apresentado no IX Congresso Brasileiro de Psicologia do Desenvolvimento - CBPD, João Pessoa, PB.

Bungay, H. \& Vella-Burrows, T. (2013). The effects of participating in creative activities on the health and well-being of children and young people: a rapid review of the literature. Perspect Public Health, 133(1):44-52.

Castro, L.R. (1998). Por uma teoria da infância na contemporaneidade. Em L.R. Castro (Org.), Infância e Adolescência na Cultura do Consumo (pp. 23-53). Rio de Janeiro: Nau Editora.

Chaves, A.M. \& Lordelo, L.R. (2012). Crianças e adolescentes trabalhadores: breve análise da literatura. Entre ideias: Educação, Cultura e Sociedade, 16, 61-83.

Corazza, S.M. (2004). História da infância sem fim. ljuí, RS: Editora Unijuí.

Covay, E. \& Carbonaro, W. (2010). After the Bell: Participation in Extracurricular Activities, Classroom Behavior, and Academic Achievement. Sociology of Education, 83, 20-45.

Crafter, S., O'Dell, L., Abreu, G., \& Cline, T. (2009).Young people's representations of 'atypical' work in English society. Children \& Society, 23, 176-188.

Dryfoos (1999). The role of the school in children's out-of-school time. Future Child, 9(2), 117-34. 
Durlak, J. A., Weissberg, R. P., \& Pachan M. (2010). A meta-analysis of after-school programs that seek to promote personal and social skills in children and adolescents. American Journal Community Psychologie, 45, 294-309.

Garaudy, R. (1980). Dançar a vida. Rio de Janeiro: Nova Fronteira.

James, A., Jenks, C., \& Prout, A. (1998). Theorizing childhood. Cambridge, UK: Polity Press.

Kremer-Sadlik, T., Izquierdo, C., \& Fatigante, M. (2010). Making Meaning of Everyday Practices: Parents' Attitudes toward Children's Extracurricular Activities in the United States and in Italy. Anthropology \& Education, 41, 35-54.

Larner, M.B., Zippiroli, L. \& Behrman, R.E. (1999). When School is out: Analysis and Recommendations. The Future of Children, 9(2), 4-18.

Lei $n^{\circ}$ 8.069, de 13 de julho de 1990 (1990, 13 de julho). Estatuto da Criança e do Adolescente. Recuperado: 17 jan. 2017. Disponível: http://www.planalto.gov.br/ccivil/LEIS/L8069.htm.

Lordelo, L.R. (2014). Children and the meanings of work: between personal culture and collective culture. Psychology \& Society, 6, 28-43.

Lordelo, L.R. (2015). School as Work or Work as School: Meanings in-Between for Children from Different Cultural Contexts. Em G. Marsico, V. Dazzani, M. Ristum, \& A. C. S. Bastos (Orgs), Educational Contexts and Borders through a Cultural Lens: Looking Inside, Viewing Outside. Cultural Psychology of Education. (Vol 1, pp. 335-344). Switzerland: Springer International Publishing.

Levey, H. (2009) Pageant Princesses and Math Whizzes: Understanding Children's Activities as a Form of Children's Work. Childhood 16 (2), 195-212

Macedo, R.S. (2006). Etnopesquisa Crítica e Etnopesquisa-Formação. Brasília: Liber Livro.

Mahoney, J.L. (2014). School Extracurricular Activity Participation and Early School Dropout: A Mixed-Method Study of the Role of Peer Social Networks. Journal of Educational and Developmental Psychology, 4 (1), 143-154.

Mahoney, J.L., Harris, A.L., \& Eccles, J.S. (2006). Organized Activity Participation, Positive Youth Development, and the OverScheduling Hypothesis. Social Policy Report, XX (IV), 3-31.

Mahoney, J.L. \& Vest, A.E. (2012). The Over-Scheduling Hypothesis Revisited: Intensity of Organized Activity Participation During Adolescence and Young Adult Outcomes. Journal of Research on Adolescence, 22 (3), 409-418.

Mancini, S.G. \& Castanho, M.I.S. (2016). Educação integral no Brasil: potencialidades e limites em produções acadêmicas sobre análise de experiências. Ensaio: Avaliação e Políticas Públicas em Educação, 24 (90), 225-248.

Matias, N. (2009). Escolas de tempo integral e atividades extracurriculares: universos à espera da Psicologia brasileira. Psicologia em Revista, 15(3), 120-139.

Melro, A. (2010). Actividades das crianças e jovens no espectáculo artístico e desportivo: a infância na indústria do entretenimento. Revista Pedagógica Unochapecó, 12 (24), 9-29.

Miller, P. (2005). Useful and Priceless Children in ContemporaryWelfare States. Social Politics: International Studies in Gender. State and Society 12 (1), 3-41.

Montandon, C. (2001) Sociologia da infância: balanço dos trabalhos em língua inglesa. Cadernos de Pesquisa, 112.

Qvortrup, J. (1987). Introduction. The Sociology of Childhood. International Journal of Sociology, 17 (3), 1-16.

Qvortrup, J. (2001). O trabalho escolar infantil tem valor? A colonização das crianças pelo trabalho escolar. Em L. R. Castro (Org), Crianças e jovens na construção da cultura (pp. 129-152). Rio de Janeiro: Nau Editora/FAPERJ.

Qvortrup, J. (2005). Varieties of Childhood. Em J. Qvortrup (Org), Studies in Modern Childhood: Society, Agency, and Culture (Vol. 1, pp 1-20). New York: Palgrave Macmillan.

Santana, J.P. \& Lordelo, L.R. (2014). Crianças e infâncias normativas: reflexões a partir da Psicologia do Desenvolvimento e da Sociologia da Infância. Anais Eletrônicos - II Simpósio Luso-Brasileiro de estudos da Criança. Recuperado: 08 mai. 2015. Disponível: http:// www.estudosdacrianca.com.br/site/anaiscomplementares.

Saramago, S.S.S. (2001). Metodologias de pesquisa empírica com crianças. Sociologia, Problemas e Práticas, 35, 9-29.

Sarmento, M.J. (2007). Visibilidade social e estudo da infância. Em V. M. R. Vasconcellos \& M. J. Sarmento (Orgs), Infância (in)visível. Araraquara, SP: Junqueira \& Marin Editores.

Sarriera, J.C., Tatim, D.C., Coelho, R.P.S., \& Bucker, J. (2007). Uso do Tempo Livre por Adolescentes de Classe Popular. Psicologia Reflexão e Crítica, 20(3), 361-367.

Sirota, R. (2001). Emergência de uma sociologia da infância: evolução do objeto e do olhar. Cadernos de Pesquisa, 112.

Zelizer, V.A. (2005). The Priceless Child Revisited. Em J. Qvortrup (Org), Studies in Modern Childhood: Society, Agency, and Culture (Vol. 1, pp 1-20). New York: Palgrave Macmillan. 


\section{Sobre as autoras}

Anna Paula Brandão (brandaoanna.paula@gmail.com)

Psicóloga pela Universidade Federal da Bahia - Salvador, Bahia.

Lia da Rocha Lordelo (lialordelo@gmail.com)

Doutora em Psicologia (UFBA). Universidade Federal do Recôncavo da Bahia (UFRB).

Este trabalho é fruto de pesquisa realizada através do Programa Institucional de Bolsas de Iniciação Científica (PIBIC), que concedeu uma bolsa à primeira autora. 